Vol.01/ No. 02

Pages: $61-70$

https://www.irojournals.com/iroiip/

DOI: https://doi.org/10.36548/jiip.2019.2.001

\title{
IMAGE DETECTION, CLASSIFICATION AND RECOGNITION FOR LEAK DETECTION IN AUTOMOBILES
}

Dr. Samuel Manoharan, Professor, Department of Electronics, Bharathiyar College of Engineering and Technology, India. Email: jsamuel@,bcetedu.in

\begin{abstract}
The Demands in quality of the automobile production grows at a rapid pace with the pressure to reduce costs of the automobiles further. So it becomes necessary to subject the critical components for the leakage detection to enhance the overall quality and the customer satisfaction. Apart from the conventional methods and the recently evolved methods in leakage detection for the automobiles, the paper tries to put forth a novel method for the detection of the leakage in the automobiles using the image processing techniques. The proposed method concentrates on the image detection, classification and recognition for the leak detection of the air conditioning in the automobiles. The proposed method of image detection is evaluated using the MATLAB to evince accuracy in the leakage detection, classification and recognition
\end{abstract}

Keywords: Leakage Detection, Automotive Industries, Image Detection, Classification and Recognition.

\section{INTRODUCTION}

The air conditioner in the automobile is an evaporative cooler, and often referred as the swamp coolers. It is constructed with the refrigeration system that cools down the air by including the parts such as compressor and the condenser etc. [1-3]. Along with the air circulation system and the distribution and a control system that takes care of the cool air circulation in the vehicle utilizing the air duct and many other necessary components and the controls the temperature in the vehicle [4-7] by monitoring the temperature and regulating the refrigeration system. The fig. 1 shows the overall design of the air-condition system used in an automobile [8-9]. 
Journal of Innovative Image Processing (JIIP) (2019)

Vol.01/ No. 02

Pages: $61-70$

https://www.irojournals.com/iroiip/

DOI: https://doi.org/10.36548/jiip.2019.2.001

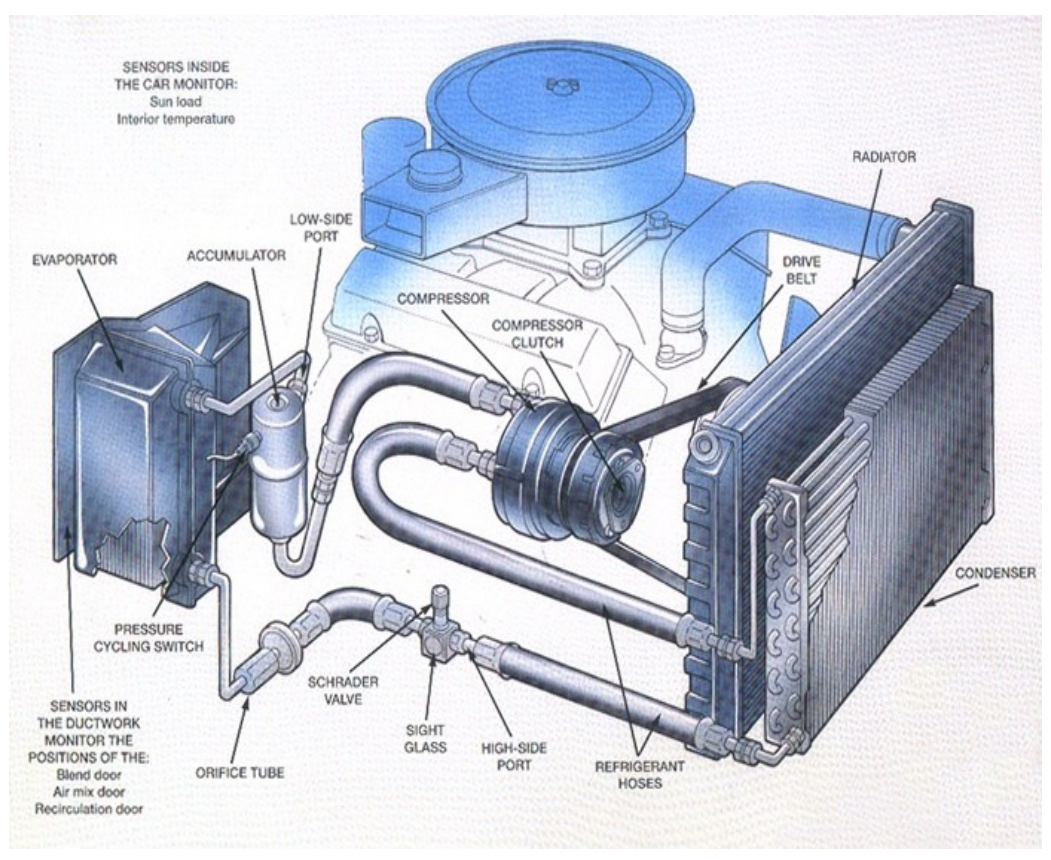

Fig.1 Air-Condition System Used In an Automobile [1]

The air conditioner in an automobile relies on the reverse Brayton or Rankine cycle for its operation, involving the components such as the compressor, evaporator, condenser, receiver-dehydrator and the connecting lines that includes the expansion valve, suction throttling valve, orifice tube, evaporator pressure value, positive operating absolute valve, thermal sensor, cycling compressor and the high pressure cut off switch.

It works similar to the air conditioning system by compressing the refrigerant vapor from the evaporator. The compressor converts the refrigerant pressure into the vapor and the vapor is discharged to condense using the condenser. The condenser liberates the heat and transforms it into the liquid form and eludes the heat from it before reaching the in line filter in the AC that evades the remains in it. Finally the cooled refrigerant moves to the lowpressure side of the system with the help of the expansion valve or the orifice tube and absorbs the heat from the air that moves across the evaporator fins and moves back to the compressor leaving the area cool.

But the most common causes for the malfunctioning of the air condition system in the automobiles are the leaks in the refrigerant circuit, which leads to an unobserved drop in the filling level, bringing down the performance and even damaging the system. As it is very difficult for the experts to make sure whether it is a leak or a normal loss 
Journal of Innovative Image Processing (JIIP) (2019)

Vol.01/ No. 02

Pages: $61-70$

https://www.irojournals.com/iroiip/

DOI: https://doi.org/10.36548/jiip.2019.2.001

careful leak detection is must.

To detect the leakage in the refrigerant circuit, the methods such as the (i) contrast agent and UV lamp, (ii) Electronic leak detection and the (3) leak detection with the forming gas are utilized and the parts such as the compressor, condenser, evaporator, filter-dryer, pressure switch, service connection and the expansion valve are tested.

All the methods used can detect the only the larger leaks in the easily accessible locations. The small amounts of leaks in the inaccessible locations are left undetected. In order to detect, classify and recognize the smaller level leaks in the inaccessible location the paper utilizes the image processing techniques for the leak detection in the automobile.

The testing procedures are and the leaks in the automobile are captured to create an image set. The captured images are subjected to the Pre-processing [11-13] process that removes the noises and the unwanted details from the image, the region of interest are extracted from the image. Further the multi class LSTSVM classifier is utilized to classify the leak detection from the normal loss [14-16].

The remaining of the paper is arranged with the section 2. Related works, section 3. Proposed work, section 4 result evaluation and section 5 conclusion.

\section{EXISTING SYSTEM [2]}

This section provides the existing system for the leakage detection in the air conditioning in the automobiles. As mentioned above the (i) contrast agent and UV lamp, (ii) Electronic leak detection and the (3) leak detection with the forming gas are utilized and the parts such as the compressor, condenser, evaporator, filter-dryer, pressure switch, service connection and the expansion valve are tested to identify the leaks in the air conditioning. Some of the method used is listed in the table. 1 below 
Journal of Innovative Image Processing (JIIP) (2019)

Vol.01/ No. 02

Pages: 61- 70

https://www.irojournals.com/iroiip/

DOI: https://doi.org/10.36548/jiip.2019.2.001
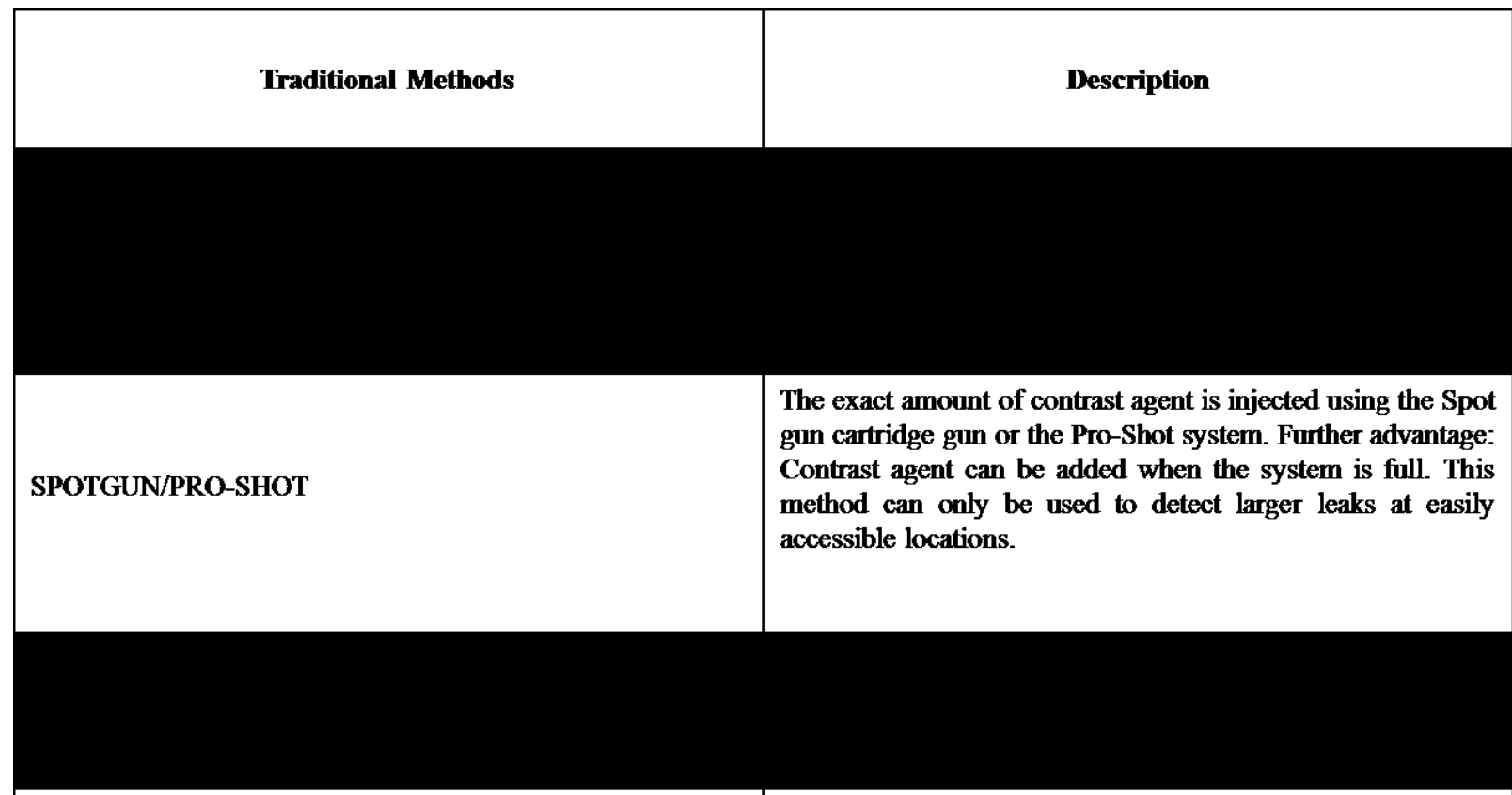

\section{ELECTRONIC LEAK DETECTION USING A LEAK DETECTOR}

LEAK DETECTION USING A FORMING GAS LEAK INDICATOR
Indicates leaks via acoustic signal. It detects halogen gases and uncovers even the tiniest of leaks at points that are difficult to reach (e.g. evaporator leaks). This method can only be used to detect larger leaks at easily accessible locations.

To detect leaks, the empty air-conditioning system is filled with forming gas, a mixture of $95 \%$ nitrogen and $5 \%$ hydrogen. The components are checked for leaks using a special electronic leak indicator. Due to the fact that hydrogen is lighter than air, the sensor needs to be moved slowly above the suspected leak (electrical connections/components). After the end of the leak detection, the forming gas can be released into the ambient air. This method can only be used to detect larger leaks at easily accessible locations. 
Table .1 Traditional Methods of Leak Detection

\section{PROPOSED METHODOLGY FOR LEAK DETECTION IN AIR-CONDITIONER}

The proposed method utilizes the image processing techniques to detect the automobile air-conditioning leaks that are very small and present in the inaccessible locations. The image acquired during the leakage testing is subjected to the Bayesian filter [6] along with the adaptive type -2 fuzzy systems to remove the noises in it [7]. Further the Multi Populated Genetic Algorithm (MPGA) is used in the features selection and the mean weight least square twin support vector machine [14] is utilized to classify the normal loss from the leakage. The flow diagram below in the fig. 2 shows the phases involved in the image detection, classification and the recognition for identifying the leak detection in the automobile.

\begin{tabular}{|c|c|c|c|c|}
\hline $\begin{array}{c}\text { Leakage } \\
\text { Testing } \\
\text { images }\end{array}$ & \begin{tabular}{|c} 
Pre- \\
processing \\
using the \\
Bayesian filter \\
with Adaptive \\
Type-2 Fuzzy \\
System
\end{tabular} & $\begin{array}{c}\text { Feature } \\
\text { selection with } \\
\text { the Multi } \\
\text { populated } \\
\text { Genetic } \\
\text { algorithm }\end{array}$ & $\begin{array}{l}\text { Classification } \\
\text { using mean } \\
\text { weight least } \\
\text { square twin } \\
\text { support vector } \\
\text { machine }\end{array}$ & $\begin{array}{l}\text { Unusual small } \\
\text { leakages in } \\
\text { the } \\
\text { inaccessible } \\
\text { places are } \\
\text { identified }\end{array}$ \\
\hline
\end{tabular}

Fig.2 Proposed Flow Diagram

Testing Images: The set of 2218 images of leakage testing in the air-conditioning in the automobiles were acquired from the quality test section of the automotive industry.

Pre-Processing: The images acquired were pre-processed to enhance the quality of the image and eliminate the 
Journal of Innovative Image Processing (JIIP) (2019)

Vol.01/ No. 02

Pages: $61-70$

https://www.irojournals.com/iroiip/

DOI: https://doi.org/10.36548/jiip.2019.2.001

noises found in it in the form of the salt, pepper and the Gaussian; this was done using the Bayesian filter integrated with the adaptive Type-2 fuzzy system the equation (1) shows the Bayes rule.

$$
P\left(\frac{\theta}{D}\right)=\frac{P\left(\frac{D}{\theta}\right) P(\theta)}{P(D)}
$$

Where $\theta$ is the Bayes rule parameter and $D$ is the observed data. The equation (2) and (3) presents the union of the type -2 fuzzy sets.

$$
\begin{gathered}
\mu_{x \cup y}(A)=\mu_{x}(A) \sqcup \mu_{y}(A) \\
\mu_{x}(A) \sqcup \mu_{y}(A)=\sum_{i j}\left(f\left(u_{i}\right) \wedge g\left(v_{j}\right)\right) /\left(u_{i} \wedge v_{j}\right)
\end{gathered}
$$

The intersection type- 2 fuzzy sets are represented using the equation (4) and (5)

$$
\begin{gathered}
\mu_{x \cap y}(A)=\mu_{x}(A) \sqcap \mu_{y}(A) \\
\mu_{x}(A) \sqcap \mu_{y}(A)=\sum_{i j}\left(f\left(u_{i}\right) \wedge g\left(v_{j}\right)\right) /\left(u_{i} \wedge v_{j}\right)
\end{gathered}
$$

If two membership grades are available then the result is as shown in the equation (6)

$$
\sum_{i j}\left(f\left(u_{i}\right) \wedge g\left(v_{j}\right)\right) /\left(1-u_{j}\right) \vee\left(u_{i} \wedge v_{j}\right)
$$

The equation (1) (2) and the (4) are applied over the observed data to elude the noises present in the images.

Feature Selection: The multi -populated genetic algorithm that is population based involving the process of selection, recombination, mutation and the reinsertion is utilized in the feature selection process. The fig. 3 below shows the steps involved in the feature selection using the multi-populated genetic algorithm. 
Journal of Innovative Image Processing (JIIP) (2019)

Vol.01/ No. 02

Pages: $61-70$

https://www.irojournals.com/iroiip/

DOI: https://doi.org/10.36548/jiip.2019.2.001

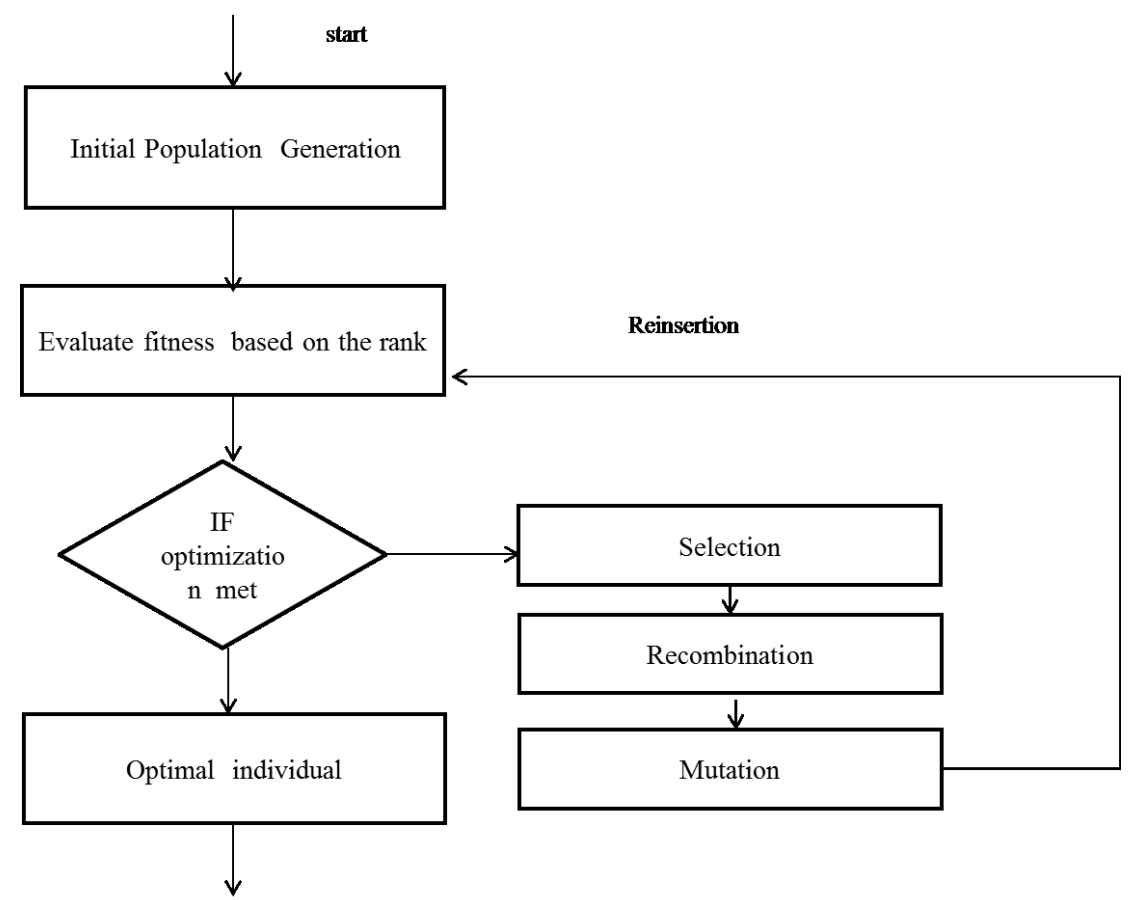

Fig.3 Multi-Populated GA

Classification: The information gained in the features selection is utilized in the learning phase of the mean-weight LSTSVM; the trained SVM is tested with the real time scenarios to classify the leakage from the normal loss. The training and the testing procedure of the LSTSVM is listed below in the table. 2

\begin{tabular}{|l|l|}
\hline Learning Phase & $\begin{array}{l}\text { Defines two matrices based on the } \\
\text { normal loss and the actual } \\
\text { leakage. } \\
\text { Select the penalty parameter } \\
\text { based on the } w \cdot x_{i}+b \geq 1 \text { and } \\
\text { the } w \cdot x_{i}+b \leq-1 \\
\text { Evaluate the hyper plane } \\
\text { parameters } \\
\text { Determine the hyper plane. }\end{array}$ \\
\hline Testing & $\begin{array}{l}\text { The testing is done in the real } \\
\text { time, classifies the normal loss } \\
\text { and the leakage in the air } \\
\text { conditioning. }\end{array}$ \\
\hline
\end{tabular}


Journal of Innovative Image Processing (JIIP) (2019)

Vol.01/ No. 02

Pages: $61-70$

https://www.irojournals.com/iroiip/

DOI: https://doi.org/10.36548/jiip.2019.2.001

Table. 2 Training and the Testing phase using the LSTSVM

\section{RESULTS}

The image detection, recognition and the classification for the leakage detection in the air-conditioning system of the automobiles through the proposed method was tested in the real time and evaluated using the MATLAB to verify the accuracy in training, testing and classifying. The Table. 3 below provides the shows the accuracy achieved in training, testing as well as classifying the normal as well as the leakage.

\begin{tabular}{|l|l|l|}
\hline \multicolumn{2}{|l|}{$\begin{array}{l}\text { Accuracy of the Traditional } \\
\text { method \% }\end{array}$} & $67 \%$ \\
\hline Proposed & $\begin{array}{l}\text { Training } \\
\text { Accuracy \% }\end{array}$ & $95 \%$ \\
\cline { 2 - 3 } & $\begin{array}{l}\text { Testing } \\
\text { Accuracy\% }\end{array}$ & $96 \%$ \\
\cline { 2 - 3 } & $\begin{array}{l}\text { Classification } \\
\text { Accuracy \% }\end{array}$ & $98 \%$ \\
\hline
\end{tabular}

Table.3 Comparison of the Accuracy Achieved In the Traditional and the Proposed Method

\section{CONCLUSION}

The paper proposes the image detection, recognition and the classification for the leakage detection in the airconditioning system of the automobiles by utilizing the Bayesian filter integrated with the adaptive Type-2 fuzzy system for the filtering the noises in the images gathered, involving the multi -populated genetic algorithm that is population based involving the process of selection, recombination, mutation and the reinsertion in the feature 
Journal of Innovative Image Processing (JIIP) (2019)

Vol.01/ No. 02

Pages: $61-70$

https://www.irojournals.com/iroiip/

DOI: https://doi.org/10.36548/jiip.2019.2.001

selection process and the mean weight least square twin support vector machine in the process of classification. The results obtained shows that the proposed method shows a considerable increase in the accuracy when compared to the actual accuracy attained in the traditional methodology.

\section{References}

[1] https://www.mech4study.com/2015/09/car-air-conditioning-system.html

[2] https://www.hella.com/techworld/uk/Technical/Car-air-conditioning/Car-air-conditioning-leak-detection1831/\#

[3] https://www.aamcocolorado.com/3-reasons-why-automakers-care-about-leak-detection-technology/

[4] Särkkä, Simo. Bayesian filtering and smoothing. Vol. 3. Cambridge University Press, 2013.

[5] Bhalaji, N. "PERFORMANCE EVALUATION OF FLYING WIRELESS NETWORK WITH VANET ROUTING PROTOCOL." Journal of ISMAC 1, no. 01 (2019): 56-71.

[6] Deisenroth, Marc Peter, Ryan Darby Turner, Marco F. Huber, Uwe D. Hanebeck, and Carl Edward Rasmussen. "Robust filtering and smoothing with Gaussian processes." IEEE Transactions on Automatic Control 57, no. 7 (2011): 1865-1871.

[7] Azar, Ahmad Taher. "Overview of type-2 fuzzy logic systems." International Journal of Fuzzy System Applications 2, no. 4 (2012): 1-28.

[8] Smys, S., and G. Ranganathan. "ROBOT ASSISTED SENSING, CONTROL AND MANUFACTURE IN AUTOMOBILE INDUSTRY." Journal of ISMAC 1, no. 03 (2019): 180-187.

[9] Duraipandian, M. "PERFORMANCE EVALUATION OF ROUTING ALGORITHM FOR MANET BASED ON THE MACHINE LEARNING TECHNIQUES." Journal of trends in Computer Science and Smart technology (TCSST) 1, no. 01 (2019): 25-38.

[10] Smys, S., Robert Bestak, and Joy Iong-Zong Chen. "Special issue on evolutionary computing and intelligent sustainable systems." (2019): 1-1.

[11] Smys, S., Jennifer S. Raj, and Nixon Augustine. "AUTONOUMOUS VEHICLE NAVIGATION IN COMMUNICATION CHALLENGED ENVIRONMENTS-A SIMULATION APPROACH." (2011).

[12] Raj, Jennifer S. "A COMPREHENSIVE SURVEY ON THE COMPUTATIONAL INTELLIGENCE TECHNIQUES AND ITS APPLICATIONS." Journal of ISMAC 1, no. 03 (2019): 147-159.

[13] Roth, Michael, Tohid Ardeshiri, Emre Özkan, and Fredrik Gustafsson. "Robust Bayesian filtering and smoothing using student's $t$ distribution." arXiv preprint arXiv:1703.02428 (2017).

[14] Chen, Jing, and Guangrong Ji. "Multi-class LSTSVM classifier based on optimal directed acyclic graph." In 2010 The 2nd International Conference on Computer and Automation Engineering (ICCAE), vol. 3, pp. 100-104. IEEE, 2010.

ISSN: 2582- 4252 
Journal of Innovative Image Processing (JIIP) (2019)

Vol.01/ No. 02

Pages: $61-70$

https://www.irojournals.com/iroiip/

DOI: https://doi.org/10.36548/jiip.2019.2.001

[15] Yu, Qing, and Lihui Wang. "LSTSVM-PBT Multi-class Classification." DEStech Transactions on Engineering and Technology Research mimece (2016).

[16] Priya, V. Shenbaga, and D. Ramyachitra. "Modified Genetic Algorithm (MGA) based feature selection with Mean Weighted Least Squares Twin Support Vector Machine (MW-LSTSVM) approach for vegetation classification." Cluster Computing: 1-13. 